\title{
L'arte è il contrario della disintegrazione. El poder creador de la destrucción en la poética de Elsa Morante
}

\section{(L'arte è il contrario della disintegrazione. The creative power of destruction in the poetics of Elsa Morante)}

\author{
MARA MENNELLA \\ https://orcid.org/0000-0003-2807-9067 \\ mm134@inlumine.ual.es \\ Universidad de Almería. https://ror.org/003d3xx08
}

Fecha de recepción: 30 de septiembre de 2019

Fecha de aceptación: 8 de julio de 2020

Resumen: En este artículo se analiza la poética de Elsa Morante desde un punto de vista diferente, el de la desintegración del mundo. Esta peculiar interpretación viene del análisis de uno de sus ensayos más polémicos, Pro o contro la bomba atomica. En el ensayo la autora reflexiona sobre los peligros de la desintegración en la era atómica y analiza también la fundamental tarea de los poetas en este entorno hostil. La autora también escribió el Piccolo manifesto dei comunisti, un listado de trece puntos que dan paso a un análisis sobre el poder y las razones para combatirlo.

Palabras clave: Elsa Morante. Teoría literaria.

\begin{abstract}
This article analyzes the poetics of Elsa Morante from a different point of view, that of the disintegration of the world. This peculiar interpretation comes from the analysis of one of her most controversial essays, Pro o contro la bomba atomica. In the essay, the author reflects on the dangers of disintegration in the atomic era and reflects on the fundamental task of poets in this hostile environment. The author also wrote the Piccolo manifesto dei comunisti, a list of thirteen points that give way to an analysis of power and the reasons for fighting it.
\end{abstract}

Keywords: Elsa Morante. Literary theory. 


\title{
MARA MENNELLA
}

\section{Introducción}

No podemos imaginar la literatura italiana contemporánea sin la contribución de una de las mayores escritoras del siglo XX, Elsa Morante. Nacida en Roma en 1912, desde la escuela primaria escribe cuentos y obras de teatro. Durante toda su vida se dedica a la composición, pero publica solo cuatro novelas (Menzogna e sortilegio en 1948, L'isola di Arturo en 1957, La Storia: romanzo en 1974, Aracoeli en 1982), tres recolecciones de cuentos (Le bellissime avventure di Caterì dalla trecciolina en 1942, Il gioco segreto: racconti en 1945, Lo scialle andaluso en 1963) y las antologías de poesías Alibi en 1958 y Il mondo salvato dai ragazzini e altri poemi en 1968. Comparada con la producción del marido Alberto Moravia, que publicó más de treinta novelas en casi el mismo período de tiempo, notamos como Elsa Morante tiene una producción menos extensa, pero no por eso menos densa y comprometida socialmente.

Elsa Morante vivía intensamente su trabajo, que consideraba más bien una vocación. Su forma preferida de manifestar esa vocación es a través de las novelas:

\begin{abstract}
Sono più autobiografici i romanzi di qualsiasi altra cosa si possa raccontare di sé" ("Novels are the most autobiographical thing to tell about oneself'), Morante explains in her 1972 interview to Enzo Siciliano, "perché nei romanzi avviene come nei sogni: una magica trasposizione della nostra vita, forse anche più significativa della vita stessa, perché arricchita dalla forza dell'immaginazione. La mia vita sta in Menzogna e sortilegio, nell' Isola di Arturo (Zagra 2014: 36).
\end{abstract}

La autora estima las novelas como la posibilidad de vivir la vida real, pero de una forma mejorada. La vida, para Elsa Morante, está hecha de encuentros y desacuerdos. Por lo tanto, entendemos que la vida para ella no es nada optimista y que se desarrolla sin eventos realmente felices. La pureza del arte se puede encontrar también en la aceptación de las pulsiones de la naturaleza, para que estas pulsiones se puedan reconocer como naturales y, entonces, inocentes. Desde el principio, Elsa Morante tiene muy claro el papel que los artistas necesitan desempeñar en el mundo. Como explica Cazalé Bérard (2014):

Il compito dell'artista, poeta o romanziere consiste per lei nell'assunzione di una responsabilità collettiva universale, come quella degli antichi bardi, dei cantastorie, dei poeti dall'innocenza primigenia. Una rivendicazione di 
L’arte è il contrario della disintegraz̧ione. El poder creador de la destrucción en la poética...

responsabilità, che va di pari passo con il ricorso all'io recitante (protagonista e interprete), in quanto alibi (parola e concetto centrali nella sua poetica) (Cazalé Bérard 2014: 79).

El sentimiento de responsabilidad a la que hace referencia Cazalé Bérard atormenta a Morante durante toda su vida como escritora y lo analiza tanto en su intervención acerca del estado de la cuestión sobre las novelas, Sul romanzo, (presentado por primera vez en 1959 en la revista Nuovi Argomenti') como en su discurso más comprometido y que analizaremos en este artículo, Pro o contro la bomba atomica (que mantuvo en 1965). Sin embargo, la calidad del arte es catártica y por eso revolucionaria. Cualquier momento de la experiencia actual se vuelve en la poesía como un momento religioso, y en este sentido sí se puede hablar de optimismo. El arte y la experiencia de la realidad se convierten en algo religioso, una iluminación mística que casi llevan al éxtasis. Esta iluminación divina se encuentra también en una de las numerosas notas que la autora deja en sus cuadernos, en este caso en uno de los primeros empleados para la redacción de Menzogna e sortilegio.

Dio mio grazie a te le parole diventano illuminanti, da una sola parola nascono immagini viventi, meravigliose storie. La ricerca suscita una vista improvvisa, di un mondo inaspettato, non mio, ma in te sorda, stupida sempre e in questo momento. Grazie tu $\mathrm{mi}$ scegli come piccolo strumento (Menzogna IV) (Morante in Chillemi 2014: 40).

La investigación de la palabra perfecta abre una nueva visión del mundo que, sin intervención divina, se quedaría atrapada en la mente del artista, encerrada en vivir el momento presente sin poder pensar en otras imágenes e historias.

\section{La tarea de los poetas}

La conciencia de responsabilidad colectiva, siempre presente en Morante, se hace más manifiesta en los años 60. Cesare Garboli identifica el cambio entre una Elsa Morante ligada todavía a la gracia de la infancia — que se manifiesta sobre

${ }^{1} \mathrm{El}$ artículo fue escrito por Elsa Morante en respuesta a nueve preguntas sobre la novela que los directores de la revista Nuovi Argomenti, Alberto Moravia y Alberto Carrocci, plantearon a varios autores de la época (Italo Calvino, Eugenio Montale y Pier Paolo Pasolini, entre otros). Las preguntas de los directores reflejan su percepción de un cambio histórico en la literatura, ligado a una posible crisis de la novela y a su abandono de la objetividad, característica del siglo XIX. 


\section{MARA MENNELLA}

todo en Il mondo salvato dai ragazzini (1968) - y una mujer que abandona las ilusiones de crecimiento de los años 50:

Elsa archivia se stessa, intuisce che non è più il tempo, in
letteratura, di intrattenersi col sublime (magari Menæogna e
sortilegio e L'isola di Arturo). Sente, vede, che il problema è
un altro: la poesia come azione, intervento, scelta tra un
progetto di vita e un progetto di morte. Il saggio va letto
come un autoritratto problematico, il drammatico 'che
fare? di uno scrittore-poeta innamorato della realtà
(Garboli 1987: XIX).

Antes de todo, Elsa Morante no concibe la posibilidad de que el arte pueda estar lejos de la realidad. Para ella, el trabajo del intelectual no puede ir al mismo tiempo que el del entretenimiento:
L'evasione non è per me, per il poco tempo che mi è dato in questa vita; io non cerco altro che la realtà, intendendo questa parola nel suo significato dovuto, e cioè la sostanza profonda e viva delle cose, di là dalla superficie labile e volgare delle apparenze. Volgare, già, mi piace insistere su questo aggettivo, poiché per me 'irrealtà' è sinonimo di volgarità, e dunque di cosa insana e ripugnante. Ai films, come ai libri, come alla pittura, come a ogni altra espressione umana io chiedo la realtà, cioè un impegno assoluto e disinteressato verso la vita (Morante 2017: 117).

La autora declara que ella no quiere huir de la vida cotidiana. Con su tarea de escritora no solo no quiere escaparse de las dificultades, sino que quiere profundizar en el conocimiento más allá de la vulgaridad de las apariencias. Como explica en el párrafo anterior, la irrealidad es vulgar y por esa razón, repugnante. En cada expresión de arte, ella pide que esté presente la realidad que, en sus palabras, es un compromiso desinteresado con la vida.

Para Elsa Morante la finalidad del arte es la de convertir su realidad poética y su belleza a través de la realidad de los objetos. Como la escritora afirma: "É inteso da tutti come questa verità è l'unica ragione del romanzo come di ogni arte" (Morante 1987: 45).

Está claro que la poética de Elsa Morante nace de la observación de la realidad, por muy destructiva que esa realidad parezca. Sin embargo, a lo largo de su carrera literaria Elsa Morante ha dejado muy pocos escritos sobre sus ideas de teoría literaria, su poética o sobre su empeño como escritora. Las ideas sobre la 
L’arte è il contrario della disintegraz̧ione. El poder creador de la destrucción en la poética...

literatura se pueden deducir de algunos artículos e intervenciones públicas, de sus diarios o en sus cartas y apuntes archivados en la Biblioteca Nacional de Roma. Es precisamente en sus cuadernos en donde se encuentran pistas preciosas, empezando por los primeros dedicados a la composición de Menzogna e sortilegio. Esta obra es monumental y una apuesta completa. Elsa Morante, en plena Segunda Guerra Mundial y posguerra, tiempos de realismo en la literatura, se dedica a la composición de una novela fantástica. Menzogna e sortilegio cuenta la vida de Elisa, huérfana, que inventa la historia de su familia a través de unas cartas ocultas que la llevan a autoconvencerse de la realidad de la mentira inventada por ella. Menrogna e sortilegio, primera novela de Elsa Morante, colecciona éxito de crítica y público y gana el Premio Viareggio en 1948.

Sin embargo, la composición de la novela no fue tarea fácil. Comenzó en 1942 y no fue interrumpida ni siquiera por la huida de Elsa Morante y Alberto Moravia de Roma debido a las redadas contra los antifascistas en la capital italiana. Una de las preguntas que la autora seguramente se hizo mientras escribía escondida en las colinas cerca de Roma fue la de entender el papel de los artistas en tiempos difíciles como los de la guerra. Eso explicaría una frase que encontramos en la portada del undécimo cuaderno que la autora utiliza para escribir la obra en 1945: "Vedere il tutto nel piccolo è l'esigenza dell'arte (Goethe)"2. La autora cita al escritor alemán Johann Wolfgang von Goethe y, aunque no podamos identificar la obra citada, podemos relacionar la frase con un pensamiento que Elsa Morante comparte con Goethe: ver el todo en lo pequeño es la exigencia del arte. Ya desde su debut como novelista, la autora no subestima ni el poder de su obra ni la responsabilidad que ella tiene como artista. Con la frase de Goethe, la autora parece declarar que con su tarea de escritora no solo no quiere escaparse de las dificultades, sino que quiere adentrarse en el conocimiento más allá de la vulgaridad de las apariencias.

Esta responsabilidad la lleva a profundizar todavía más en el compromiso que los artistas —o poetas, según las palabras de la escritora — deben tener hacia el mundo y la sociedad:

È compito dei poeti di rinnovare continuamente il mondo agli occhi degli uomini, che l'abitudine rende ciechi e distratti davanti alle cose, di rispiegare loro le cose con sempre nuove immagini, questo è il compito dato ai poeti quel sabato in cui Egli, finita la creazione, si riposò. Io ho

${ }^{2} \mathrm{El}$ fragmento manuscrito se encuentra en la página web Le stanæe di Elsa, editado por la Biblioteca Nacional de Roma y está disponible en línea en: http://193.206.215.10/morante/mes/1619_1100001.html 


\section{MARA MENNELLA}

creato il mondo - disse - voi dovete far sì che esso sia giovane e nuovo per gli uomini in eterno - Da qui l'immortale necessità della poesia, senza poesia l'uomo muore di inedia. 22 maggio 1945 (Elsa Morante in Zagra 2019: 17).

La autora reflexiona también sobre la tarea del poeta y de la poesía, palabras que ella utiliza para referirse al arte en general, en el mundo actual. Notamos que la escritora se refiere al papel del poeta como el encargado de renovar las imágenes del mundo en los ojos de los hombres, tapados por los hábitos de cada día que los distraen. Además, en este fragmento se yuxtaponen la religión y el papel del arte en el mundo. Ella afirma que el arte nació en el sábado de la creación, el día después del nacimiento del hombre, y Dios dio a los poetas la importante tarea de hacer que el mundo fuese joven en la eternidad. El arte tiene entonces un comienzo hierático y sagrado que le otorga inmortalidad y un papel fundamental: mantener viva la humanidad, porque sin poesía el hombre se muere de inedia, o sea de hambre y debilidad.

Vemos entonces que el poeta no tiene una labor fácil, ya que su misión es salvífica. Al mismo tiempo, el poeta debe tener en cuenta que tiene que ver el mundo desde su perspectiva, para darle novedad a la humanidad y que esta pueda seguir viva. Además, el poeta está llamado a una misión más importante todavía: la de la resistencia frente a una sociedad que no comprende su trabajo y alaba la ausencia de razón.

El sueño de la razón produce monstruos. E in poche epoche, come nella presente, il sonno della ragione è stato assecondato, cullato, lusingato. Perfino le macchine prodotte dalla scienza, che dovrebbero rappresentare i monumenti della ragione, si riducono, invece, a dispensieri inerti di questo sonno senile. Ed è logico, allora, che, dentro una simile industria del sonno, la vera arte sia guardata come un'intrusione sovversiva, e poco raccomandabile (Morante 1987: 70).

Citando a Goya, Morante reflexiona sobre la razón y la peligrosidad de dejar que la falta de razón sea elogiada, contrariamente a lo que pasa con el verdadero arte que termina por ser visto como algo poco recomendable y contrario al progreso. Esta visión destructiva del arte por parte de la colectividad se pone en antítesis con lo que la autora identifica como la verdadera amenaza a la 
L'arte è il contrario della disintegraz̧ione. El poder creador de la destrucción en la poética...

humanidad: la desintegración a manos de progreso tecnológico, identificado con la bomba atómica.

\section{La bomba atómica como expresión de la contemporaneidad}

En los años 60, cuando ya tiene dos novelas publicadas y es reconocida como autora de prestigio, Elsa Morante cada vez esconde menos su conciencia política, la que la llevará a escribir La Storia (1974), una novela ambientada en la Roma de la Segunda Guerra Mundial y en la que su protagonista, Ida Ramundo, se encuentra sola frente a los acontecimientos históricos y a la repercusión que esos acontecimientos tienen en las vidas de los individuos.

Para entender mejor por qué Elsa Morante decidió dar su opinión hay que enmarcar la vida de la autora en la época histórica que se estaba viviendo en su país. Las décadas de los 60 y de los 70 en Italia se presentan como conflictivas; el país viene de un boom económico que ha modificado tanto su aspecto económico como el demográfico (un tercio de la población cambió de residencia), creando casi de repente una clase obrera más consciente de sus derechos y un movimiento estudiantil que reflexionaba sobre la modernidad de un país todavía posbélico. La debilidad de la clase política del tiempo, en crisis después de la restauración de la democracia en 1945, abrió paso a una época de atentados, reivindicados por grupos de extrema derecha e izquierda, que culminó en el homicidio del presidente de la Democrazia Cristiana Aldo Moro en 1978 por parte de las Brigadas Rojas y en el atentado de la estación de Bolonia el 2 de agosto de 1980, del que todavía no se han identificado los instigadores (Sabatucci; Vidotto 2007).

En este clima de incertidumbre y de cambios históricos, Elsa Morante ya no se esconde: su deseo es el de exaltar el valor de la belleza y del arte, desvelando la verdadera cara de la sociedad que vive en la era de la incertidumbre de la supervivencia por la amenaza de desintegración del mundo ante la presencia de armas como las bombas atómicas.

Una de las contribuciones más importantes sobre la poética de la autora y su posición política viene de la conferencia Pro o contro la bomba atomica que mantuvo en tres ciudades en Italia - Turín, Milán y Roma- en 1965. En estas conferencias la autora une la reflexión sobre el descubrimiento del poder destructivo de la bomba atómica — que ella cuestiona sobre si realmente sea nuevo o no- a la importancia del arte en el mundo. Esta intención de juntar algo destructivo como la bomba atómica y el arte es subrayada por la escritora misma, ya que afirma que el argumento de la bomba atómica es algo que tiene que preocupar a los "escritores", o poetas, a no ser que sean "hombres de letras": los hombres de letras solo se preocupan de la literatura, mientras los escritores o 


\section{MARA MENNELLA}

poetas se definen como "un uomo a cui sta a cuore tutto quanto accade, fuorché la letteratura" (Morante 1987: 97). Vemos aquí entonces una de las primeras definiciones de poética de Elsa Morante: los escritores son hombres y mujeres empeñados, conscientes de la actualidad y de lo que pasa a su alrededor, pero que no hacen de su profesión, la literatura, el centro de su pensamiento y acción. Es una declaración profundamente política, en el significado del adjetivo más ligado a su etimología, la de intervenir en los asuntos públicos y de preocuparse de la interacción entre las personas.

La escritora también cuestiona la posibilidad de analizar el adjetivo "atómico" en el significado de "minúsculo", en total contraste con la inmensa destrucción que la bomba atómica y sus consecuencias producen en el mundo. Pero Elsa Morante en su análisis sigue más allá: la bomba atómica es una de las expresiones de la sociedad contemporánea, como los diálogos de Platón son el espejo de la sociedad griega, el Coliseo de la Roma Imperial, "i campi di sterminio della cultura piccolo-borghese burocratica già infetta da una rabbia di suicidio atomico" (1987: 99). Poner en paralelo algo tan grande e histórico, tan importante y fundamental para la humanidad como las contribuciones de Platón o del mundo romano con los campos de exterminio nos hace reflexionar: la destrucción también es parte de la realidad y de la historia.

\subsection{La desintegración como herramienta para llegar al nirvana}

En Pro o contro la bomba atomica, la autora no deja sin responsabilidades a la cultura pequeño-burguesa burocrática, la clase influyente en las tomas de decisiones, como infectada por la rabia de un suicidio atómico, y en este caso el adjetivo es utilizado como sinónimo de infinitesimal. Con esta interpretación, no podemos dejar de pensar que lo que la autora quiere decir es que el deseo de autodestrucción está dentro del ánimo humano. Como interpreta Lucamante (2014):

[Elsa Morante] reveals the existence of an undeniable process: a not so 'hidden temptation of disintegrating themselves' is what humanity has done with the progressive elimination of politics intended as freedom but understood, rather, in terms of an administrative machine whose only tasks are bureaucracy and exercise of force against the Other (Lucamante 2014: 94).

La política, según Morante, en su desarrollo desde Platón hasta la actualidad, ha tenido una trayectoria conforme al crecimiento del deseo de autodestrucción de la humanidad. La política pasa de la expresión máxima de la libertad a ser una 
L'arte è il contrario della disintegraz̧ione. El poder creador de la destrucción en la poética...

simple expresión de la burocracia para poder ejercer su fuerza contra los demás: "esse, il nostro tesoro atomico mondiale, non sono la causa potenziale della disintegrazione, ma la manifestazione necessaria di questo disastro, già attivo nella coscienza" (Morante 1987: 100). Entonces, Elsa Morante remarca su visión de que no será la bomba atómica la causa de la destrucción de la sociedad, sino que esa es más bien la expresión de deseo de autodestrucción de la humanidad y, sobre todo, de los que están en el poder.

En Pro o contro la bomba atómica también está presente un punto de reflexión relativo a la religión como posible relación entre grupos de poder y autodestrucción. Elsa Morante introduce el tema del nirvana: en algunas religiones, como el hinduismo, este estado de liberación del sufrimiento se alcanza normalmente con la contemplación. Sin embargo, la burguesía contemporánea aspira al nirvana "attraverso la disintegrazione della coscienza, per mezzo della ingiustizia e demenza organizzate" (1987: 100). Notamos entonces cómo para la escritora, el problema de la destrucción adquiere un significado casi religioso: el deseo de autodestrucción de la humanidad no solo está intrínseco en el ánimo humano, sino que también es algo a lo que una parte de la humanidad, la clase dirigente, tiende para marcar su poder y ascender a un estado espiritual libre de cualquier condicionamiento.

\section{E1 arte como antídoto a la destrucción}

Siguiendo su reflexión sobre la influencia de la tendencia a la autodestrucción del hombre, la escritora ofrece su propia definición del arte: "L'arte è il contrario della disintegrazione" (Morante 1987: 101), el arte es lo contrario de la desintegración. Con estas palabras se quiere manifestar que el arte es el antídoto necesario contra la destrucción no solo física del mundo, sino sobre todo de la desintegración moral de la humanidad.

La ragione propria dell'arte, la sua giustificazione, il suo solo motivo di presenza e sopravvivenza, o, se si preferisce, la sua funzione, è appunto questa: di impedire la disintegrazione della coscienza umana, nel suo quotidiano, e logorante, e alienante uso col mondo; di restituirle di continuo, nella confusione irreale, e frammentaria, e usata dei rapporti esterni, l'integrità del reale, o in una parola, la realtà (1987: 101-102).

El mundo, en su continua relación con las consecuencias del poder, se corrompe y lleva a la alienación a todos los hombres que pierden el contacto con la realidad, con la esencia verdadera de sus vidas. Para un escritor no es fácil llegar 


\section{MARA MENNELLA}

a entender cómo reflejar con sus palabras la realidad: para llegar a la madurez desde el punto de vista artístico, según Elsa Morante, hay que experimentar todas las angustias de la vida, pero asimilarlas como propias, no sufrirlas: "Avere assimilato, però, significa un arricchimento, e non una intossicazione, o un ingorgo" (1987: 55). Es importante que el artista no se deje llevar en sus obras por sus sufrimientos porque su visión de la realidad estaría viciada por su recorrido de dolor. El artista es capaz de encontrar la verdad dentro de la realidad, pero a veces no es capaz de comunicarlo. Esta falta de conciencia no es un problema para la autora, ya que "le loro verità, piuttosto che per se stessi, essi le scoprono per gli altri” (1987: 48). El poeta tiene entonces el privilegio de poder ver la realidad con ojos diferentes y poder contarla para que la humanidad pueda quitar la capa que está encima de la verdad, la que puede ayudar a que la destrucción del mundo no pase. Para ella, el arte es lo contrario de la desintegración y su función es la de impedir esa desintegración.

Difatti, nella laida invasione dell'irrealtà, l'arte, che viene a rendere la realtà, può rappresentare la sola speranza nel mondo. [...] La qualità dell'arte è liberatoria, e quindi, nei suoi effetti, sempre rivoluzionaria. [...] Qualsiasi momento dell'esperienza, reale e transitoria, diventa, nell'attenzione poetica, un momento religioso (1987: 101-102).

Su función, según la autora, es la de devolver a la humanidad la integridad de lo real y la realidad, ya que con el bullicio de la vida cotidiana se puede perder tanto el contacto con la realidad como la integridad y la unidad de esa realidad amenazada por la irrealidad.

Hemos hablado del arte como antídoto a la destrucción, pero la autora reflexiona tanto sobre el peligro en el que se puede incurrir si el arte no se pone en contra de la desintegración, como del papel que podría desempeñar el arte dentro del sistema de la desintegración: "Ma allora, bisognerà porsi una domanda: poiché l'arte non ha ragione se non per l'integrità, quale ufficio potrebbe assumersi dentro il sistema della disintegrazione? Nessuno" (1987: 102). Puede parecer una pregunta un poco peculiar, pero es un punto de vista legítimo. Si hasta ahora hemos visto cómo la desintegración nace por la corrupción del mundo, también el arte puede dar su contribución a esa corrupción cuando no cumple con su función de búsqueda de la realidad. Pero si el mundo va hacia su desintegración como último objetivo, ¿qué papel quedaría para el artista? Según Morante, el artista tiene dos elecciones: una guiada por Eros, y la otra por Tánatos, dos fuerzas ancestrales y creadoras que en la poética de Elsa Morante juegan un papel fundamental y que nos hace concebir la tarea del artista como 
L'arte è il contrario della disintegraz̧ione. El poder creador de la destrucción en la poética...

todavía más religiosa. Eros, la pasión, puede engañar al artista y hacerle imaginar que está desempeñando su tarea de búsqueda de la realidad, pero esta función realmente no se está cumpliendo y el artista se sentirá disgustado por eso; en este caso, el error está del lado del artista, o sea que lo cumple él por creer en Eros. Tánatos, al contrario, es un error de los contemporáneos: Tánatos crea imágenes monstruosas para engañar las conciencias y alejarlas de la búsqueda de la verdad:

Così che, ridotti alla elementare paura dell'esistenza, nella evasione da se stessi e quindi dalla realtà, loro, come chi ricorre alla droga, si assuefanno all'irrealtà, che è la degradazione più squallida, tale che in tutta la loro storia gli uomini non hanno conosciuto mai l'uguale. Alienati, poi anche nel senso della negazione definitiva; poiché per la via della irrealtà non si arriva al Nirvana dei sapienti, ma proprio al suo contrario, il Caos, che è la regressione infima e la più angosciosa (1987: 102-103).

La consecuencia de esta intervención de Tánatos es el caos, debido a una serie de actos humanos que nacen de un simple miedo: el miedo a la existencia misma. Este miedo aleja de la necesidad de búsqueda de la realidad y lleva a los artistas a portarse como unos drogadictos que buscan en los estupefacientes una escapatoria a la realidad. La escritora condena duramente a las personas que ceden al consumo de drogas porque, al estar marginados por esta adicción, no pueden alcanzar el nirvana. Además, incurren en una degradación completa a la que no se puede poner remedio. Sin embargo, para la autora hay una vía de salvación para el artista: el ascetismo para poder salvarse del contagio:

Sarà sempre meglio un soggetto reale (fosse anche l'unico
superstite) pensante in cima a una colonna, piuttosto che
un soprannumerario oggetto conciato, televisato e lustrato
per la bomba atomica. Anzi, secondo una logica intuitiva
degli eventi, finché quello lì resiste a scrivere poesie sulla
colonna, la bomba atomica stenterà a scoppiare (1987: 104).

En esta idea optimista se juntan algunos de los pensamientos más importantes de Elsa Morante que, aunque en sus novelas y composiciones deje reflejar los puntos más oscuros del alma humana, consigue encontrar el por qué esta se arrastra hasta el fondo, para volver a subir y ver la luz. Y esta luz, en la era de la bomba atómica, es la amenaza de la destrucción. Tarea del artista, aunque se quede solo para no ser corrupto por el mundo, es poner en alerta al resto de la 


\section{MARA MENNELLA}

humanidad para que esta no se autodestruya. Esto puede suceder, aunque el poeta no se aísle, pero tiene que ser capaz de resistir al desastre que le espera a la humanidad. Y, en este caso, el poeta que tiene conciencia de su empeño moral y social se convierte en un puerto seguro para los hombres porque él, gracias a su posibilidad de ver el mundo de forma diferente, puede desvelar los engaños:

Anche senza accorgersene, per necessità del suo istinto, il poeta è destinato a smascherare gli imbrogli. E una poesia, una volta partita, non si ferma più; ma corre e si moltiplica, arrivando da tutte le parti, fin dove il poeta stesso non se lo sarebbe aspettato (1987: 105).

De ese puerto seguro, la poesía, con su tarea de desvelación de los engaños, sale a toda vela, multiplicándose y llegando donde ni siquiera el poeta podría haber imaginado.

La autora también ofrece un ejemplo de lo que para ella es un artista que pudo llegar a descubrir la realidad. En Pro o contro la bomba atomica cita al poeta húngaro Miklos Radnoti, asesinado muy joven en campo de concentración. A su lado se encontraron unos versos y Elsa Morante se quedó fascinada por la aventura humana del hombre-artista:

"Ora la morte è un fiore di pazienza". E così ci è rimasta, miracolosamente, la prova, che pure dentro la macchina 'perfetta' della disintegrazione, che lo annientava fisicamente, la sua coscienza reale rimaneva integra (1987: 109).

Lo que más fascina a la autora es la actitud de Radnoti frente a su muerte anunciada. En los días previos a su fusilamiento, el poeta vio caer a sus compañeros, pero eso no lo llevó a derrumbarse, sino a cumplir hasta el final su misión de artista. Y esa misión de artista sigue cumpliéndose decenios después, mientras la máquina de muerte de campos de concentración se ha autodestruido.

E la scoperta che questo ragazzo ha potuto esistere sulla terra, per me è stata una notizia piena di allegria. L'avventura di questo ragazzo assassinato è uno scandalo inaudito per la burocrazia organizzata dei lager, e delle bombe atomiche. Scandalo non per l'assassinio, che è nel loro sistema. Ma per la testimonianza postuma di realtà (l'allegria della notizia) che è contro il loro sistema (1987: 110). 
L'arte è il contrario della disintegraz̧ione. El poder creador de la destrucción en la poética...

La destrucción de campos de concentración, de la bomba atómica y de todas las guerras que hubo y que sigue habiendo en el mundo es algo que no se puede parar. Pero el arte, en su misión de búsqueda de la integridad, siempre es revolucionario y sobrevive a los intentos de desintegración.

En tiempos de tregua social, como explica la autora, el artista tampoco puede descansar porque la máquina de la desintegración sigue activa y sigue identificando a los poetas como un peligro: intentarán o cambiarlos para que parezcan mundanos o alienarlos para que no sean vistos como profetas.

Andranno dicendo, per esempio, che non è moderno. Per forza! difatti nel loro concetto, essere moderni significa essere disintegrati, o in via di disintegrarsi. Andranno dicendo magari che non si occupa di cose serie, né della realtà; e si capisce! giacché il sintomo principale della disintegrazione, di cui loro sono succubi o malati, consiste nell'assumere come realtà il suo contrario (1987: 111).

La principal manera de desacreditar a los artistas será la de utilizar sus propias armas: no serán considerados modernos, o sea estarán en contra de la innovación, y no se encargarán de dar una nueva visión a la realidad. Pero ese es el sistema de la desintegración que no entiende lo que es la realidad: no es el mundo como lo vemos nosotros, sino lo que se revela después de la acción del poeta.

La autora también divide el mundo de las letras en dos grupos: hay scrittori e scrivent $i^{3}$, los segundos marcados por su oficio de escribir sin pensar en la influencia que sus palabras puedan tener en el mundo o, simplemente, cómplices de un sistema que les hace devenir propaganda del sistema destructivo de la bomba atómica. Además, los scrittori tienden a ser partisanos de las clases sociales explotadas, ya que "il dominio di una persona su un'altra, se è stato sempre iniquo, ormai è pure, definitivamente, acquisito come irreale" (1987: 114): una vez más, el verdadero escritor tiende a cumplir su misión de búsqueda de la realidad, que en este caso se encuentra en las injustas relaciones sociales.

\footnotetext{
${ }^{3}$ Los términos scrittori y scriventi se podrían traducir al español como "escritores" y "escribientes". La definición proporcionada por el Diccionario de la Lengua Española de la RAE corresponde a la que entiende Elsa Morante en su obra, o sea la de "persona que tiene por oficio copiar o poner en limpio escritos ajenos, o escribir lo que se le dicta" (Real Academia Española: "escribiente"). Sin embargo, en el Diccionario de la Lengua Española también hay una segunda definición, que corresponde a "escritor". Esto no corresponde al italiano, en el que el término scrivente (Treccani: scrivente) solo refleja quien cumple el hecho de escribir. Por esta razón se ha preferido mantener la forma italiana y no la traducción española.
} 


\section{MARA MENNELLA}

Además de encontrar compañía en los grupos subversivos, el poeta encuentra una relación de almas con otro grupo de personas, los jóvenes y los niños: "Soltanto loro, difatti, riconoscono e frequentano ancora la realtà. Per legge universale, e peggio che mai nel sistema, la maggioranza degli adulti sono contaminati più o meno dall'irrealtà, e quindi, ostili" (1987: 115). El tema de la niñez y de su cercanía a la esencia de la vida es recurrente en la trayectoria de Elsa Morante. La autora no esconde que desde muy pequeña se acercó a las letras, casi como para puntualizar que escribir no es ningún juego de niños, y los personajes que construye son muy jóvenes - como Arturo en L'isola di Arturo- o desean volver a su infancia por su pureza y cercanía a la creación de la vida — como Manuele en Aracoeli.

Remarcando la honestidad como base de la poesía, Elsa Morante sigue definiendo el producto de la lucha del poeta contra la sociedad. ¿Qué poesía tiene que escribir el poeta?

La risposta è semplice: scriverà, onestamente, "resta da fare la poesia onesta". Però, basterebbe dire la poesia; perché, se è poesia, non può essere che onesta. Un poeta, in quanto tale, non può non essere onestom (1987: 116).

La poesía, en cuanto reveladora de la verdad, es honesta y honesto también es el poeta. Al terminar su discurso, Elsa Morante determina por qué es tan importante reflexionar sobre la tarea del poeta, la honestidad de la poesía y la importancia de la realidad.

Contro la bomba atomica non c'è che la realtà. E la realtà non ha bisogno di prefabbricarsi un linguaggio: parla da sola. Perfino Cristo ha detto: non preoccupatevi di quel che direte, o di come lo direte. E' la realtà che dà vita alle parole, e non il contrario (1987: 117).

La respuesta de Elsa Morante, además de revelarnos finalmente — como si pudiese haber dudas - su postura hacia la bomba atómica, nos revela además otro detalle importante: el poeta no tiene que buscar palabras para definir la realidad, porque ella habla sola. Y una vez más el discurso se hace religioso, mencionando a Cristo y su idea de que es la realidad la que hace las palabras y no al contrario.

Si hay un punto débil en Pro o contro la bomba atómica es el hecho de quedarse demasiado superficial con respecto a lo que Elsa Morante habría podido analizar: "il punto debole di questo saggio sta proprio nella sua logica: inferiore, inadeguata 
L'arte è il contrario della disintegraz̧ione. El poder creador de la destrucción en la poética...

rispetto alla complessità misteriosa e fantastica del grande amore di Elsa per la realtà" (Garboli 1987: XVIII). Los entresijos de la realidad se mezclan tanto con el misterio de la creación literaria como con los avances tecnológicos que nos enajenan de la verdad.

Cada uno de nosotros, y más todavía los que quieran dedicarse a las letras, tiene que elegir de qué lado presentarse: a favor de la destrucción, proporcionada por la bomba atómica, o en contra de la desintegración, del lado de la poesía, aunque esto signifique una vida más difícil por poder ser considerado un alienado y en antítesis con el poder que gobierna el mundo.

\section{La reflexión sobre el poder en la era de la bomba atómica}

"Il potere [...] è degradante per chi lo subisce, per chi lo esercita e per chi lo amministra" (Morante 1974: 342). El poder, según Davide, uno de los protagonistas de La Storia, es degradante para quien lo sufre, quien lo ejerce o administra. Pero esta es una de las pocas veces en la escritura de Elsa Morante en las que podríamos decir que es realmente la autora la que habla y no su personaje. Con la madurez adquirida con los años y las experiencias vividas personalmente, la escritora ya no esconde su personal visión de la sociedad y de los problemas de los hombres. Para que Davide pueda coger la voz de la escritora, Elsa Morante hizo un camino de reflexión tanto público como privado: "Nessuna persona viva rimane esclusa dall'esperienza dal sesso, dell'angoscia, della contraddizione e della deformazione. E le alternative del destino sono la miseria o la colpa, la diserzione o l'offesa" (Morante 1987: 108).

Una de las consideraciones que Elsa Morante lleva a cabo a raíz de Pro o contro la bomba atomica nunca vio la luz mientras estaba en vida. Piccolo Manifesto dei Comunisti (senza classe né partito) es una pequeña reflexión en 13 puntos sobre los movimientos estudiantiles de 1968 y los que intentaban hacer la revolución. El manifiesto, redactado probablemente en 1970, fue encontrado en sus escritos por Cesare Garboli y Paolo Cecchi y publicado en la revista italiana Nottetempo en 1988.

El primer punto recuerda al Manifiesto comunista de Marx y Engels de 1848: "Un mostro percorre il mondo: la falsa rivoluzione" (Morante 2004: 1). En los puntos siguientes define lo que son el honor y el deshonor para el hombre. "Il disonore dell'uomo è il Potere. Il quale si configura immediatamente nella società umana, universalmente e da sempre fondata e fissa sul binomio: padroni e servi - sfruttati e sfruttatori” (2004: 3). Para Elsa Morante el máximo deshonor para el hombre es el poder, entendido como relación de sometimiento entre explotadores y explotados. El honor, sin embargo, se obtiene a través de "la libertà di spirito" (2004: 2) y la autora entiende "espíritu" lejos de su significado 


\title{
MARA MENNELLA
}

religioso, especificando que ella concibe así la realidad natural del hombre, que no está corrompido por el poder. Con estas palabras notamos cómo la autora defiende a las personas que para ella son verdaderamente libres, las que pueden expresarse siguiendo su verdadera naturaleza. El "honor del hombre", sigue la autora, se debe garantizar a todos los hombres, pero esta necesidad no se puede llevar a cabo hasta que existe el poder. La moralidad es algo intrínseco a la naturaleza del hombre, y de allí el empleo de palabras tan marcadas como "honor" y "deshonor". Las palabras no son casuales: Elsa Morante quiere remarcar el significado más puro de honor y deshonor, estrechamente conectado con la virtud y la moralidad, o sea

\begin{abstract}
verso il mondo della dedizione, della vocazione e del 'sacrificio' del politico per la comunità e la rexpubblica. L'uso che, quindi, la scrittrice fa della parola 'onore', legato alla virtus, non ha niente a che vedere con la violenza dei gruppi settari e mafiosi dell'Italia del Novecento, ma piuttosto con una condotta politica ed etica, quella che dovrebbe reggere ogni pratica pubblica, veramente e democraticamente umana (Martínez Garrido 2012: 404).
\end{abstract}

A partir de ese punto, Morante mueve su enfoque hacia lo que ella identifica como el máximo deshonor, el poder, que se construye en el binomio amo y siervo, explotados y explotadores. Para que ya no haya poder se tiene que hacer una revolución, y aquí se conecta el primer punto del manifiesto: el peligro de las falsas revoluciones. La autora denuncia esas falsas revoluciones, cuya manifestación final no es nada más que la violencia por principio dogmático contra el capitalismo (Martínez Garrido 2012). Las verdaderas revoluciones son las que se oponen al poder sin pedir nada a cambio: el único objetivo tiene que ser liberarse completamente de ello. No puede existir una revolución para reafirmar el poder de una manera diferente, ni puede existir una revolución cuyo objetivo sea algo místico como "le glorie nazionali" (Morante 2004: 10) prometidas por los fascismos.

La escritora marca los peligros de una sociedad basada en el desprecio de los humanos: por mucho que se hagan revoluciones, en nombre de cualquier bandera, estas no pueden estar fundadas en la humillación de las personas porque esto solo puede crear más personas explotadas. Además, utilizar las personas más desafortunadas para poder llegar al poder es la peor manera de explotación: "Servirsi a fini di potere degli sfruttati (anche solo del loro nome) è la peggiore forma di sfruttamento possibile" (2004: 17). 
L'arte è il contrario della disintegraz̧ione. El poder creador de la destrucción en la poética...

Asimismo, las masas tienen el poder no solo de cambiar el estado de la sociedad, sino también de exaltar o no tanto el poder como la libertad de espíritu:

Una folla consapevole che afferma la libertà dello spirito è uno spettacolo sublime. E una folla accecata che esalta il Potere è uno spettacolo osceno: chi si rende responsabile di una simile oscenità farebbe meglio a impiccarsi (2004: 17).

El mejor espectáculo es ver a la muchedumbre poder afirmar su libertad. Sin embargo, quien exalta el poder se mancha de un error imperdonable que, según la autora, no merece más que la muerte. Las expresiones tan fuertes que ella emplea tienen la intención de despertar las conciencias, sobre todo de los movimientos de izquierdas, demasiado adormecidos frente a los riesgos de nuevos totalitarismos.

Además, según Elsa Morante, es importante que, si el espíritu libre detecta que su vocación es la de luchar contra el poder, tiene la obligación de actuar, aunque esté solo. En el punto 13 de Piccolo Manifesto dei Comunisti Elsa Morante deja claro su punto de vista:

Niente va perduto (v. il granello di senape e il pizzico di lievito); e, in conseguenza, chiunque schiavizza, sotto qualsiasi pretesto, il proprio spirito, si fa agente con questo del disonore dell'uomo (2004: 18).

Nada de lo que un espíritu libre del poder hace se pierde. Intentar detener esta vocación de rebelión es para la escritora una forma de esclavitud y un deshonor que se encuentra al mismo nivel del deshonor que sufren los esclavos del poder.

No sabemos si Elsa Morante se consideraba una revolucionaria. Cierto es que, para ella, los revolucionarios no siempre han sido aceptados por la sociedad y normalmente han pagado con su propia vida su rebelión. De hecho, el sacrificio es algo que tienen en común algunos de los revolucionarios listados por ella en el Piccolo manifesto: "Cristo, Socrate, Giovanna D'Arco, Mozart, Cechov, Giordano Bruno, Simone Weil, Marx, Che Guevara" (2004: 18). Además, las acciones enumeradas como actos de rebeldía van desde algo que puede ser considerado inocente, como un estudiante o un profesor que se ponen en contra de una doctrina humillante para el ánimo humano, hasta actos casi de terrorismo como el herrero que fabrica clavos para parar los vehículos nazis. Para ella no hay diferencia, ya que "simili opere, o azioni, nell'affermare, ciascuna coi propri 


\section{MARA MENNELLA}

mezzi, la libertà dello spirito contro il disonore dell'uomo, sono tutte allo stesso titolo belle e morali" (2004: 18).

Martínez Garrido (2012) interpreta el manifiesto desde un punto de vista filosófico:

L'estetica nel Piccolo Manifesto ha come principale funzione l'attivazione della coscienza etica, in rapporto all'amore e alla pietà. In questo modo, l'arte libera l'uomo da ogni schiavitù, avvicinandolo a Dio, la cui reale manifestazione si trova nella libertà di coscienza individuale (Martínez Garrido 2012: 407).

Según Martínez Garrido, la principal función del Piccolo manifesto es la de declarar una vez más de qué manera el arte puede liberar al hombre de su esclavitud, como también pasa en el discurso Pro o contro la bomba atomica; la finalidad principal siempre es la de la reflexión sobre el arte y el mundo en el que el arte se desarrolla. Esta visión puede ser una explicación también del por qué en el Piccolo manifesto — que es de todas formas un escrito incompleto- no encontramos el modelo de sociedad deseado por Elsa Morante. Esta falta de posición se puede interpretar por la desilusión por la incompetencia de la clase política de la época junto con su deseo de encontrar una forma universal de que los hombres sean verdaderamente libres. Sin embargo, hay una carta que nunca fue enviada, la Lettera alle brigate rosse, en la que especifica su visión acerca de las instituciones:

A chi per caso avesse letto i miei ultimi libri, sarebbe nota quale stima io faccia delle società istituite. Ma per quanto inette e corrotte possano venir giudicate certe società presenti, io mi auguro di non vivere abbastanza per assistere a nuovi totalitarismi (2004: 17-18).

En esta carta, escrita después del secuestro de Aldo Moro, Elsa Morante habla de los peligros de los totalitarismos, tanto de izquierdas como de derechas, y de las acciones violentas que para ella siempre son manifestación de fascismos. La autora declara "non solo la sua più assoluta preoccupazione riguardo alla sofferenza della vittima, ma persino la sua 'materna pietà' nei confronti dell'alienazione esistenziale dei carnefici di Aldo Moro" (Martínez Garrido 2012: 417). El miedo de la escritora es el de volver a ver dictaduras que nacen de la corrupción de las sociedades y de las ineptitudes de sus gobernantes. 
L’arte è il contrario della disintegraz̧ione. El poder creador de la destrucción en la poética...

Una società instaurata nel totale disprezzo della persona umana, qualsiasi nome voglia darsi, non può essere che oscenamente fascista [...] Da una simile società ormai non possono nascere che generazioni di castrati e servi (Morante 2004: 19).

A finales de los 70, Elsa Morante empieza a utilizar el adjetivo "fascista" para referirse a cualquier tipo de política que no pueda mejorar la existencia humana. Como subraya Martínez Garrido (2012):

Per la scrittrice, quindi, la formazione della persona umana richiede dell'autentica libertà democratica. Perciò, rifiutando ogni forma di violenza, Elsa Morante ebbe persino il coraggio di definire, fin da allora, come 'fascista' qualsiasi società che, disprezzando la libertà e la dignità della persona umana, si servisse della legge coercitiva e violenta del potere totalitario (Martínez Garrido 2012: 416).

La res publica no puede tener futuro si nace corrupta en su fundamento: la del respeto hacia las personas para que puedan desarrollar libremente su espíritu.

\section{Conclusiones}

Elsa Morante es una autora única en su tiempo, siempre en búsqueda del equilibrio perfecto entre la moralidad y la perfección estética de sus obras. Con las palabras de Martínez Garrido (2012: 420), Elsa Morante es "una scrittrice e una pensatrice minoritaria, un'intellettuale (forse delle più notevoli) fuori scuola, diversa ed eterodossa riguardo al canone estetico e politico dell'Italia del suo tempo".

Morante no podía entender el arte como algo separado de la realidad del mundo y en este artículo hemos podido analizar sus ideas sobre el poder creador del arte: no es ninguna casualidad que la mayor contribución a su poética haya sido titulada Pro o contro la bomba atomica. En esta, la desintegración anunciada da pie a la posibilidad para los artistas de poder desarrollar su ser más profundo, para poder remarcar su total libertad. Sin embargo, la tarea no es fácil porque la tendencia general de la humanidad, como hemos visto, es la desintegración y quienes intentan evitarla son considerados peligrosos revolucionarios.

Las máquinas como la bomba atómica han sido creadas con un uso impropio de la razón, el que tiende a la autodestrucción. El verdadero arte llega en socorro para poder salvar el mundo de la desintegración y, sobre todo, para poder salvar 


\section{MARA MENNELLA}

a quienes son víctimas del sueño de la razón. Nos deja entonces con una pregunta: ¿valdrá la pena?

\section{Referencias bibliográficas}

CAZALÉ BÉRARD, Claude, "Senza i conforti della religione: il romanzo impossibile. Scritture al limite". En: Cuadernos de Filología Italiana, 21, 2014, pp. 75-89.

CHILlEMI, Francesco, "In the Realm of Lie". En: Elsa Morante's Politics of Writing: Rethinking Subjectivity, History, and the Power of Art. Nueva Jersey: Fairleigh Dickinson University Press, 2014, pp. 43-55.

Garboli, Cesare, "Prefazione". En: Morante, Elsa, Pro o contro la bomba atomica. Milano: Adelphi, 1987.

LuCAMANTE, Stefania, “The World Must be the Writer's concern". En: Lucamante, Stefania, Elsa Morante's Politics of Writing: Retbinking Subjectivity, History, and the Power of Art. Nueva Jersey: Fairleigh Dickinson University Press, 2014, pp. 88-103.

MARTÍNEZ GARRIDO, Elisa, "Sentire il mondo, pensare la realtà. Due scritti politici di Elsa Morante". En: Poetiche. Reviste di lettura, 14, 36, 2012, pp $397-$ 422. .

Morante, Elsa, La Storia. Torino: Einaudi, 1974.

__ , "Sul romanzo". Pro o contro la bomba atomica. Milano: Adelphi, 1987.

_- Piccolo manifesto dei comunisti (senza classe né partito). Milano: Edizioni Nottetempo, 2004.

—_L La vita nel suo movimento. Recensioni cinematografiche, 1950-1951. Torino: Ed. de Goffredo Fofi, Einaudi, 2017.

SABBATUCCI, Giovanni; VIDOTTO, Vittorio, Il Mondo contemporaneo dal 1848 a oggi. Roma-Bari: Laterza, 2007.

ZAGRA, Giuliana, "Writing: A Lifelong Affair". En: Lucamante, Stefania (ed.), Elsa Morante's Politics of Writing: Rethinking Subjectivity, History, and the Power of Art. Nueva Jersey: Fairleigh Dickinson University Press, 2014, pp. 32-42.

ZAGRA, Giuliana, La tela favolosa. Carte e libri sulla scrivania di Elsa Morante. Roma: Carocci Editore, 2019.

REAL ACADEMIA ESPAÑOLA, Diccionario de la lengua española, 23. ${ }^{a}$ ed., [versión 23.3 en línea]. Disponible en línea en: https://dle.rae.es/escribiente

TRECCANI, "Escrivente". En: Vocabolario. Disponible en línea en: http://www.treccani.it/vocabolario/scrivente 